\title{
Panel calls for overhaul of AIDS research
}

Washington. A lengthy, long-awaited and often critical report by a 118-member panel of scientists and other experts has called for a major revamping of the \$1.4-billion AIDS research programme of the National Institutes of Health (NIH), which it says has been poorly focused and uncoordinated.

The report recommends that NIH scientists be stripped of strategic control over vaccine research, and that funding for AIDS research by non-NIH scientists be doubled. The new money would come in part from work wrongly labelled as AIDS-related. The report also wants drug discovery efforts scaled back, on the grounds that many duplicate the drug industry's work

At the same time, the report calls for more basic research, especially in immunology, prevention and opportunistic infections, in a programme that consumes 12 per cent of NIH's budget. It suggests that a mishmash of clinical trials be consolidated into a single network, and describes as "critical" the need actively to recruit promising and distinguished scientists to a field that consumes 12 per cent of NIH spending.

The report, whose executive summary was released last week, also says that it is "crucial" for the NIH's Office of AIDS Research (OAR) to keep control over AIDS research at the NIH's 24 institutes and centres - a role that has recently been challenged by congressional Republicans. And it recommends against establishing a separate AIDS institute at the NIH.

The report is "an excellent mid-course correction" to NIH's 15-year-old AIDS research effort, says Arnold Levine, professor of molecular biology at Princeton University, who chaired the AIDS Research Programme Evaluation Working Group. The group included 90 scientists, as well as activists and representatives of the biotechnology and pharmaceutical industries.

The conclusions of the working group were unanimously accepted by the advisory council of the OAR, which commissioned the report in late 1994. Harold Varmus, the director of NIH, said that he and individual institute directors will begin consulting on responses immediately - a reaction the report calls "imperative" in order to influence budgets for 1997 and 1998.

"We will be taking these recommenda-

\section{Clinical trials launched of Salk AIDS vaccine}

Washington. Immune Response Corpora tion, the California biotechnology company co-founded by Jonas Salk, the late polio vaccine pioneer, announced last week that it has launched a phase- 3 trial of the controversial therapeutic AIDS vaccine Remune, based on an inactivated version of the AIDS virus. tions with extreme seriousness," Varmus said last week. Implementation "will take some time, but will be effective".

The report marks a watershed in AIDS research at NIH, which accounts for 85 per cent of public spending on AIDS research worldwide. While commending past NIH efforts for producing "unprecedented dividends" that have created "the first real chance" of turning AIDS from an inexorably fatal condition into a chronic, manageable disease, it is also highly critical of many aspects of that research.

The overarching theme is the need for better coordination prioritization and focusing of AIDS Levine: sees report as research, in which all 'excellent correction'. 24 NIH institutes

and centres are involved, of which the National Institute of Allergy and Infectious Disease (NIAID) consumes 42 per cent of AIDS money, and the National Cancer Institute 16 per cent.

One key recommendation is that the OAR and the institutes develop stricter definitions of AIDS and AIDS-related research. At many institutes - in particular the NCI - a "substantial" proportion of AIDS money continues to be funnelled to activities "with little or no direct relevance" to AIDS. As an example, it cites programmes to develop artificial blood substitutes by the National Heart, Lung, and Blood Institute - the US blood supply has been protected from HIV since 1985 .

The NIH also comes under fire for holding the AIDS grant purse strings too closely, channelling "simply insufficient" funds to unsolicited proposals from external scientists, in contrast to projects proposed and controlled by NIH scientists. In 1994, for example, about 20 per cent of NIH spending on AIDS research went to unsolicited proposals, compared to 50 per cent of money for non-AIDS research.

As a result, the report says, outside investigators are discouraged from proposing novel AIDS-related experiments. As a partial remedy, it calls for funds for investi-

The company says that it will enlist at least 2,500 patients at more than 50 US medical centres in an attempt to establish whether Remune delays the onset of AIDS in HIV-positive individuals. The Food and Drug Administration gave final approval for the phase-3 trials to proceed earlier this month.

M. W. gator-initiated research to be doubled, the new money coming partly from research now funded by AIDS dollars but "only peripherally related to AIDS".

Another significant recommendation is that the entire AIDS vaccine research effort be restructured, given that vaccine research has "received less funding and attention" than other areas at NIH, and that the spread of HIV worldwide means this is no longer acceptable. "In many developing nations, vaccines may be the only cost-effective way to prevent transmission," the panel writes.

In particular, it recommends establishing a trans-NIH vaccine research effort as an independent unit within the NIAID. The effort would be directed by an AIDS Vaccine Research Committee (AVRC), chaired by and composed primarily of non-government scientists. Vaccine research should return to fundamentals in the light of recent failures, Levine adds. "There haven't been enough attempts to explain why they failed," he says. "That's basic science."

The panel suggests that all AIDS clinical trials be condensed into a single network sponsored primarily by NIAID and overseen by an OAR committee to ensure coordination between the institutes. It is particularly critical of the NCI's Developmental Therapeutics Program (DTP), calling it of "limited" productivity in producing novel agents and largely replicating work by the pharmaceutical industry. Restructuring and "substantial" cuts in its AIDS funding for the DTP are "appropriate".

AIDS activists have been divided in their reaction to the report. Some have given it a warm welcome. "The nation's leading scientists have provided NIH with a clear roadmap," said Mark Harrington, a member of the working group's executive panel, and a policy analyst with a New York AIDS group.

But other activists criticized the report for not going far enough. "It completely fails to address several of the much more fundamental flaws in NIH decision-making and priorities," says Bob Lederer, a spokesman for ACT UP/New York. He complains that the report does not recommend targeting specific money to alternative therapies, that it does not recommend conflict of interest rules for NIH AIDS scientists with links to drug companies, and that it fails to call for research targeted on the needs of women and non-whites.

In addition to a 17-member executive working group, the full panel was made up of six subject review panels, which addressed the areas of aetiology and pathogenesis, drug discovery, clinical trials, vaccine research and development, behavioural, social sciences and prevention research, and natural history, epidemiology and prevention research. Their reports will be released early next month. 